\title{
LA REDUCCIÓN DE JORNADA ANUAL EN UN SECTOR DE NUEVA CREACIÓN. NI APLICACIÓN DEL CONVENIO, NI CONDICIÓN MÁS BENEFICIOSA: FALTA DE ACCIÓN. COMENTARIO A LA SENTENCIA DE LA AUDIENCIA NACIONAL, SALA DE LO SOCIAL, 128/2019, DE 31 DE OCTUBRE
}

\author{
Juan José Fernández Domínguez \\ jjferd@unileon.es \\ Catedrático de Derecho del Trabajo y Seguridad Social \\ Universidad de León
}

Patricia Prieto Padín

patricia.prieto@deusto.es

Contratada Posdoctoral de Derecho del Trabajo y de la Seguridad Social Grupo de investigación reconocido por el Gobierno Vasco (IT1089-16)

Universidad de Deusto

Resumen: Un conflicto colectivo de enjundia, como el derivado de la operatividad de una condición más beneficiosa en materia de jornada anual en supuestos de sucesión de convenios, obediente a la aparición de un nuevo sector nacional por mor de la especialización técnico-productiva, encuentra respuesta judicial de remisión a su sede apropiada al apreciar la excepción de falta de jurisdicción, de límites tan polémicos como su propia aplicación en el caso concreto.

Palabras clave: Excepción de falta de jurisdicción; Sucesión de convenios; Aparición de sector nacional; Jornada máxima anual

\begin{abstract}
A relevant collective conflict derived from the operation of a more beneficial condition in terms of the annual working hours is analysed. This, in addition, in cases of succession of collective bargaining agreements and due to the emergence of a new national sector for the sake of technical-productive specialisation. Judgment refers to its appropriate headquarters upon observing a exception of lack of jurisdiction, with limits as controversial as its own application in the specific case.
\end{abstract}

Keywords: Exception of lack of jurisdiction; Succession of succession of collective bargaining agreement; Emergence of the national sector; Maximum annual working hours 
1. Contexto legal - 2. El doble supuesto de hecho: conflicto latente y subyacente -

3. Criterio judicial auspiciado por la sentencia - 4. Incidencia futura de la doctrina comentada

\section{Contexto legal}

"La duración de la jornada de trabajo será la pactada en los convenios colectivos o contratos de trabajo". A partir de esta remisión a la autonomía colectiva o individual el art. 34.1 ET resuelve tan trascendental materia, con la sola precaución de establecer un límite superior infranqueable, por cuanto "la duración máxima de la jornada ordinaria de trabajo será de cuarenta horas semanales de trabajo efectivo de promedio en cómputo anual". A sus resultas, un total de 1826 horas con 27 minutos actúan como umbral de derecho necesario absoluto por debajo del cual será la autonomía colectiva, por lo común, la encargada de determinar esa frontera del nivel más elevado en cada caso concreto.

Precisamente el protagonismo otorgado a la negociación colectiva ofrece el triple contexto legal de la sentencia: inmediato, mediato y remoto.

En el plano inmediato, los distintos niveles de negociación eventualmente implicados en la determinación de la jornada máxima anual (arts. 82.3 y 84.2 ET) pueden conducir a conflictos más o menos amplios en función de los espacios territorial, funcional y personal afectados. La exigencia de correspondencia entre el ámbito material del conflicto y el del proceso especial ante la jurisdicción social hará que cualquier desajuste lleve a poder apreciar la concurrencia de una excepción de creación jurisdiccional: la denominada "falta de acción", como óbice formal aplicable de oficio cuando no existiera interés litigioso actual y real, inferido a partir de la falta de correspondencia entre la extensión subjetiva de la acción y su titular.

En el entorno mediato cabrá situar la estructura de la negociación y la sempiterna cuestión de los cambios de unidades con la aparición de alguna de las clausulas convencionales más difíciles de interpretar y aplicar en la práctica, como son las destinadas a ordenar las condiciones más beneficiosas de origen individual (o plural) y las decisiones que le afectan en orden a su respeto incondicionado o a la aplicación de técnicas de neutralización dadas por decisiones de compensación y absorción.

Por último, y según dejará ver de manera preclara el pronunciamiento examinado, el marco remoto lo proporciona la renovación de sectores para la negociación, como producto de las coordinadas productivas que mudan en el tiempo, en particular a partir de la irrupción de avances tecnológicos, exigencias de aplicación a la mudable realidad social y a hábitos de consumo o preferencias distintos o, sencillamente, obedientes a elementos circunstanciales subjetivos de las organizaciones sindicales y empresariales signatarias.

No existe un patrón que guíe en tal tránsito, muchas veces resultado más de la fuerza de los hechos que del Derecho; de ahí la frecuencia con la cual resulta ser el producto 
de la evolución desde un convenio extraestatutario a otro acomodado a las exigencias de la norma. En particular cabrá indicar que, si bien la disposición final $8^{\text {a }} \mathrm{ET} / 1980$ asignó a la Comisión Consultiva Nacional de Convenios Colectivos la formulación de una suerte de catálogo de actividades que pudieran "servir de indicador para las determinaciones de los ámbitos funcionales de la negociación colectiva", y tal función se mantuvo (aun cuando el catálogo nunca llego a existir) en la disposición final $2^{\mathrm{a}}$ del Texto Refundido de 1995, el cometido desapareció a resultas del evidente retroceso de la intervención administrativa en el marco de las relaciones colectivas.

De este modo, la vigente disposición adicional 9a ET/2015 únicamente atribuye a la Comisión, por cuanto aquí interesa, competencia en materia de "asesoramiento y consulta sobre el ámbito funcional de los convenios colectivos y sobre el convenio colectivo de aplicación a una empresa, así como la consulta en el supuesto de extensión de un convenio regulado en el art. 92". Facultad a desarrollar, siempre dentro de un ámbito superior al autonómico, de conformidad con lo previsto en los arts. 12 y ss. RD 1362/2012, de 27 de septiembre, cuyos dictámenes pueden ser un instrumento de asesoramiento para describir ámbitos, bien donde no hay convenio aplicable, bien donde podría tener cabida una nueva unidad especializada ratione materiae.

\section{El doble supuesto de hecho: conflicto latente y subyacente}

La aparente sencillez del caso, que por sí mismo apenas si concitaría mayor interés, no oculta tras el conflicto saliente un fondo de superior complejidad; con una tendencia, además, en evidente expansión a la luz de los cambios rápidos y profundos que afectan al sistema productivo.

De este modo, el asunto presente y directamente abordado refiere una demanda sobre conflicto colectivo suscitada por FICA-UGT (a la cual se adhieren CCOO y CIG, incorporándose por esta última organización escrito en el cual el Consejo Gallego de Relaciones Laborales manifiesta su posición favorable a cuanto reclaman las centrales sindicales) contra la Asociación Nacional de Industrias de Elaboración (ANIE), instando que la reducción de jornada contemplada en el artículo 18 del convenio colectivo que vincula a ambos (consistente en una minoración de 16 horas del total anual para 2018, elevada a 24 horas a partir de enero de 2021) sea aplicada a todos los trabajadores y empresas, sin distinción alguna. En el entendimiento, obviamente, de la existencia de algunas entidades concernidas en las cuales no se venía haciendo así; en concreto, el demandante alude a la constancia de "empresas en el sector que no están aplicando el referido precepto convencional a aquellos trabajadores a los que con anterioridad se les aplicaba un convenio colectivo diferente".

La defensa de la patronal ANIE es sencilla: el convenio está siendo aplicado a todos los trabajadores en todas las empresas, salvo cuando resultan aplicables otras condiciones más beneficiosas en virtud de lo dispuesto en el art. 6 del convenio invocado; añadiendo, a sus resultas, cómo el dato de haber sido aplicado anteriormente otro convenio en modo alguno enerva la operatividad del art. 18 cuando fuere pertinente. 
En este sentido, el último párrafo del art. 6 es claro en cuanto a que "las condiciones más beneficiosas en materia de jornada máxima (...) se mantendrán a título personal para los trabajadores afectados en tanto no se convenga otra cosa por acuerdo entre la empresa y la representación de los trabajadores o se produzca la equiparación con lo que se estipule en los próximos convenios de este ámbito sectorial”. Remitiendo, por tanto, a la constatación, caso por caso, sobre si ha acaecido aquel acuerdo o ha habido lugar a la mentada equiparación; por ende, a la valoración de la situación en cada empresa y al contraste, siempre, entre lo aplicado y lo dispuesto en el art. 18 del convenio.

Conflicto clásico de concurrencia convencional bajo el cual en ningún momento se oculta la génesis del que subyace, producto de una especialización técnica en los procesos de producción capaz, en esta concreta ocasión, de llevar a descubrir el nuevo ámbito dado por las empresas dedicadas a la elaboración de productos del mar con procesos de congelación y refrigeración.

La fuerza de los hechos, más que del Derecho, hizo que en su momento emergiera como sector distinto, despegándose del convenio del frio industrial, para así atender de manera conveniente las singularidades propias de la elaboración de productos del mar. Título bajo el cual fue negociado el primero, solo firmado por UGT, motivo por el cual su eficacia fue limitada o extraestatutaria; alcanzándose en 2008 el convenio estatutario del sector estatal de nuevo cuño.

En este tránsito es donde se plantea el problema derivado de querer disfrutar de las nuevas condiciones laborales, pero sin perder las más beneficiosas ostentadas en las unidades de origen. Dificilísima cuestión a la cual casi siempre responden los convenios a través de una cláusula ad hoc, en esta ocasión a partir del mencionado art. 6, cuyo tenor se viene reproduciendo desde la primera versión, pero no ha enervado las posiciones encontradas de sindicatos y patronal: los primeros defendiendo la singularidad de la materia relativa a reducción de tiempo de trabajo, que llamaría a un análisis separado de cualquier valoración global de condiciones; la segunda afirmando la incompatibilidad de tal aplicación con el disfrute del régimen de jornada máxima que se traía del convenio del sector del frío industrial.

Todo ello en un marco funcional y personal que, según consta en los hechos probados de la sentencia, tan solo se ha acreditado que afecte a una entidad (FANDICOSTA, SA), lo cual, y según se pasa a analizar, resulta ser el factor clave para dictar una sentencia que no resuelve sobre el fondo el asunto.

\section{Criterio judicial auspiciado por la sentencia}

El pronunciamiento aprecia de oficio la excepción de falta de acción; sin entrar, por ende, a resolver sobre el fondo del asunto. En consecuencia, únicamente pone fin formalmente al conflicto latente, remitiéndolo a cuanto considera la sede funcional apropiada para afrontarlo. 
La doctrina que contiene presenta un grueso destinado a repasar los lugares comunes de mayor interés para, a su través, fundamentar la excepción de falta de acción en su versión de carencia de interés real y actual; al lado, una escueta justificación de su aplicación en el caso en concreto.

Siguiendo una práctica que no por habitual deja de ser menos discutida, el núcleo argumental supone reproducir cuanto previamente ya había sentado el Alto Tribunal sobre la excepción procesal en un pronunciamiento precedente (STS de 22 de febrero de 2017, rec 120/2016). En vez de sistematizar, resumir o adaptar su tenor, lo refleja literalmente en toda su extensión; incorporando, de este modo, los tres aspectos fundamentales que contiene relativos a:

1.- Una síntesis de la construcción jurisdiccional más reciente sobre la denominada "falta de acción". Reconoce, de este modo, la ausencia de estatuto procesal definido de la figura, motivo por el cual su uso, por lo general impreciso, aparece en ocasiones referido a la falta de jurisdicción (casi siempre al no estar en presencia de un conflicto real o actual), aun cuando no falten otros en los cuales recoge situaciones de ausencia de legitimación activa, queda referido a una declaración de inadecuación de procedimiento o alude a las desestimaciones por insuficiencia de fundamento de la pretensión (recordando, de este modo, el tenor de la STS de 26 de diciembre de 2013). De manera más sistemática, la escasez de ese acervo consolidado, o al menos bien delimitado, por los órganos de la jurisdicción social ha llevado a una tipología que, "no en todos los casos acertadamente" -y el matiz es harto interesante-, viene siendo identificado por la jurisprudencia con alguna de las siguientes situaciones (con citas de las SSTS de 18 de julio de 2002, rec 1289/2001, 1 de marzo de 2011, rec.74/2010, y 8 de mayo de 2015, rec 56/2014, el tenor de la STS de 15 de septiembre de 2015, rec 252/2014): “A) Un desajuste subjetivo entre la acción y su titular. B) Una inadecuación objetiva del proceso elegido en relación con la pretensión ejercitada. C) La ausencia de un interés litigioso actual y real, de modo especial cuando se ejercitan acciones declarativas. D) Una falta de fundamentación de la pretensión ejercitada”.

2.- A renglón seguido, y centrando la atención sobre una de las especies mentadas, analiza si la acción ejercitada conduce a la excepción por su naturaleza meramente declarativa. A tal fin repasa el dato histórico derivado de la admisión por el Tribunal Constitucional de acciones declarativas en el proceso laboral al calor de cuanto establece el art. 24.1 CE, con la finalidad primaria de no privar a un interés legítimo de su tutela judicial (recordando la STC 71/1991, de 8 de abril, en criterio consolidado a partir de las STC 210/1992, de 30 de noviembre, y 20/1993, de 18 de enero). E igualmente remarca que tal admisión nunca fue absoluta o ilimitada, pues "está condicionada a la existencia de un interés digno de tutela. La acción meramente declarativa como modalidad de tutela jurisdiccional que se agota en la declaración de la existencia, inexistencia o modo de ser de una relación jurídica, no existe como tal si no se de una verdadera necesidad de tutela jurisdiccional cifrable en el interés en que los órganos judiciales pongan fin a una falta de certidumbre en torno a la relación jurídica de que se trate. El interés es, pues, requisito de la acción meramente declarativa, y una resolución judicial que de manera no arbitraria ni irrazonable afirme 
la inexistencia de la acción meramente declarativa por falta de interés no atenta contra el derecho a la tutela judicial efectiva (STC 210/1992, de 30 de noviembre).

La base constitucional ha servido de cimiento a una fértil doctrina en la jurisdicción social, limitando su justificación a la existencia "de un interés controvertido o discutido por las partes, por tanto un conflicto actual, dado que la función de la acción declarativa es eliminar la incertidumbre en torno a la existencia, inexistencia o modalidad de una relación jurídica" (STS de 16 de marzo de 1999, rec 2094/1999); por tanto, "la concurrencia de una verdadera controversia y la concurrencia de una necesidad de protección jurídica (...), lo cual ha de llevar a analizar el supuesto concreto a fin de evitar el planteamiento de cuestiones futuras o hipotéticas que no se corresponden con la existencia de una verdadera controversia actual entre las partes, con la consiguiente necesidad de protección jurídica de un derecho insatisfecho que deba ser tutelado mediante el ejercicio de la acción" (SSTS de 24 de junio de 2015, rec 2400/2014, y 15 de septiembre de 2015, rec 252/2014).

Sintetizando todo el acervo acumulado a lo largo de décadas, presenta el doble condicionamiento para la admisibilidad de estas demandas (STS de 29 de noviembre de 2016, rec 676/2015): " $1^{\circ}$ La existencia de una verdadera controversia. Por ello se entiende que no puedan plantearse cuestiones no actuales ni efectivas, futuras o hipotéticas, o cuya decisión no tenga incidencia alguna en la esfera de derechos e intereses del actor; se requiere que exista un caso o controversia, una verdadera 'litis', pues no cabe solicitar del Juez una mera opinión o consejo. $2^{\circ}$.- La concurrencia de una necesidad de protección jurídica. Se precisa de la existencia de un derecho insatisfecho, al que se trata de tutelar mediante el ejercicio de la acción”.

$3^{\text {o }}$ - Al final, procede a trasladar el anterior acervo a la modalidad planteada en el caso concreto. Recuerda, de este modo, cómo el proceso especial de conflicto colectivo demanda, precisamente, la existencia de una situación conflictiva: "este cauce procesal no debe, por tanto, ser utilizado como un procedimiento de consulta a los órganos de la jurisdicción social sobre unas y otras hipótesis interpretativas en supuestos en que no se ha producido en realidad, o no se ha producido todavía, una concurrencia de pretensiones incompatibles de dos o más sujetos, lo que acontece cuando de los hechos probados no se constata que haya ya existido un desacuerdo real entre las partes, y siendo ello así el proceso de conflicto colectivo planteado carece de sustrato real" (STS de 15 de diciembre de 1997, rec 1398/1997).

Tras este proceso de sedimentación, se alza el escueto pronunciamiento de la Audiencia Nacional, el cual toma en consideración dos datos. En primer lugar, la existencia de una controversia sobre la aplicación general del art. 18 del convenio, según sostiene el demandante, o de la excepción contenida en el art. 6 de aquel, conforme mantiene la patronal; de preferirlo, la distinta interpretación de la extensión del art. 18, bien generalizada, bien abierta a la matización de la posible aplicación en materia de jornada máxima anual de una condición más beneficiosa. En segundo término, y a pesar de tal dato, el hecho de haber acreditado que puede producirse tal discrepancia tan solo en una empresa, por cuestionar la aplicabilidad del art. 18 a trabajadores a quienes antes era de aplicación el Convenio del Sector de Frío Industrial. 
De este modo, la Audiencia Nacional, constatando la ausencia de un interés litigioso actual y real a partir del desajuste subjetivo entre el ámbito de la acción y su titular, establece "que concurre la excepción de falta de acción, en el ámbito sectorial en el que el presunto conflicto ha sido planteado, ya que la controversia solo se ha acreditado que queda circunscrita al ámbito de una empresa determinada, siendo allí donde el mismo debe ser planteado".

Presencia admitida de conflicto, pero con primacía de su ámbito concreto de expresión sobre la fuente de la cual deriva y cuya aplicación se discute.

\section{Incidencia futura de la doctrina comentada}

Podría pensarse que un pronunciamiento que resuelve declarando la aplicación de una excepción procesal apenas si presenta otro recorrido o interés distinto al propio y estricto de la resolución -en su caso permanente, provisional o temporal- del supuesto enjuiciado. Lejos de tal, desde estas líneas quiere efectuarse una doble advertencia:

En primer lugar, la cada vez más frecuente aplicación de la excepción de "falta de acción". El propio Tribunal Supremo ha advertido ya sobre su "utilización imprecisa", tanto más peligrosa cuando se aprecia de oficio; motivo por el cual procederá estar pendiente tanto de su frecuencia como de su correcta utilización.

En segundo término, habrá de preocupar de manera singular su aplicación en procesos de conflicto colectivo como el analizado, pues la apreciación de falta de correspondencia entre el ámbito de la acción y su titular puede llevar a una primacía excesiva del lugar donde se desarrolla el conflicto frente al ámbito del convenio a aplicar; por consiguiente, a la primacía de la legitimación derivada de aquel en detrimento de otra más cercana, ignorando, de este modo, cómo, en muchas ocasiones, los vínculos entre una y otra son evidentes o las referencias locativas inferiores pudieran carecer de sujetos para ejercer la acciones directamente.

Huelga decir que este será un panorama presumiblemente más frecuente con el tiempo, en el nuevo contexto dado por unas condiciones de producción donde el factor locativo pierde importancia también a efectos de negociación colectiva. 